\title{
Has the Revolution in Scholarly Communication Lived Up to Its Promise?
}

\author{
by Trudi Bellardo Hahn, Mariann Burright and Heidi Nickisch Duggan
}

\section{EDITOR'S SUMMARY}

In the late 1990s the need for an overhaul in the approach to scholarly publishing was recognized. A drastic change would revise the economic model on which publishing was based, give authors rights to their own works in open access repositories and enable consumers across the world to access scholarly materials, building a flow of valuable information for the common good. The revolution has yet to materialize, though small but welcome achievements have been made. The open access business model has gained a foothold with the Public Library of Science (PLOS), and scientists receiving grants through the National Institutes of Health must submit manuscripts to the PubMed Central digital archive. Several universities mandate that faculty members deposit their scholarly articles in institutional repositories, and the Compact for Open Access Publishing Equity promotes open publishing by supporting authors. Librarians are both part of the problem and part of the solution. Instead of worrying about paying rising subscription fees, they could use their position to influence authors to take advantage of open access channels despite publishor-perish pressures. Recent legislative and presidential initiatives, geared to disseminating publicly funded research, may be effective in moving open access closer to transforming the traditional system of scholarly communication.

\section{KEYWORDS}

\section{scholarly publishing}

open access publications

digital repositories

economics of information

business models

publishers

Trudi Bellardo Hahn is professor of practice at the College of Information Studies,

University of Maryland, College Park. She can be reached by email at thahn<at>umd.edu.

Mariann Burright is head, Science Collections and Scholarly Communication at the University of Georgia. She can be reached by email at mariann<at>uga.edu.

Heidi Nickisch Duggan is associate director, Galter Library, Northwestern University.

She can be reached by email at heidi<at>northwestern.edu.

\section{"Revolution: a sudden, radical or complete change"}

- Webster's Universal Encyclopedic Dictionary, 2002

W hat revolution?

Even though the term scholarly communication has been used for only about 40 years as a big umbrella term covering all the activities and norms of scholars related to creating and disseminating new knowledge, the modern idea of it has existed for nearly 400 years, since the introduction of the scholarly journal in Western Europe in the 1600s. With that radical change to the traditional modes of scholarly communication, such as writing letters and attending meetings, the processes and norms for creating and disseminating knowledge began evolving. Overall the changes came slowly, punctuated by occasional spikes, such as the tremendous increase in scholarly journals in the 19th century and after World War II; the arrival of commercial firms as major players in the publishing industry in the 1960s; and the explosion of e-publishing on the web in the 1990s.

By the late 20th century the complex issues that face scholarly communication today were well recognized, and the situation was deemed a crisis that needed a revolution, minimally consisting of three facets. First, it would transform the existing economic model of publishing, insuring financial solvency for a large and diverse group of publishers but not the raking in of huge profits by a small number of publishers. The growing gap between library budgets and the cost of materials needed by users would shrink. In the event that a publisher closed up shop, electronic materials would be preserved. In this publishing model, the most cherished elements such as quality control through peer review and added-value production processes would be sustained.

Second, the revolution would expand the legal options of authors to 
control dissemination of their own work. Authors would retain rights to deposit their published works in institutional, professional or federal agency repositories or to freely post their materials on their department or personal websites. They could send full-text copies to anyone who requested them. Thus, the current prohibitively costly and restrictive model would be replaced with an open access (OA) institutional repository model where scholars share their works with few or no legal and financial barriers.

The third miracle of the revolution would open access to scholarly materials to a vast audience that included scholars and students all around the world, the funding agencies who underwrite much of the costs of scholarly research and, actually, anyone who can search the open web. The increased access would benefit society through the spread of valuable knowledge, and it would benefit scholars themselves through increased recognition for - and citation of - their scholarly output.

\section{What direction is the revolution moving? Around or forward?}

A revolution that would overturn the existing economic model of publishing, expand authors' legal rights and open access to everyone has yet to occur, or at minimum, is moving forward with fits and starts. Evidence for and against a transformation in the scholarly communication system has co-existed for many years, making it difficult to point out a road map to transformative reform. Rather than following a straightforward trajectory to a particular point, the period 2004 to present has seen significant milestones toward reforming the scholarly communication process, but these single events that showed the potential to cause a sudden, radical or complete reform in the entire system have failed to precipitate a complete transformation.

With the launch of the Public Library of Science (PLoS) in 2003, the OA business model for scholarly publishing began to make its imprint on scholars and publishers alike. PLoS is a "nonprofit organization of scientists and physicians committed to making the world's scientific and medical literature a freely available public resource" (www.plos.org/). PLoS journals are supported by a combination of author fees (usually from grants) and foundation funding. PLoS journals are quite highly ranked, but they are not in the topmost tier of scientific journals in any discipline except for biology.
In 2008, the promise of open access reached a high point with the implementation of the mandated National Institutes of Health (NIH) Public Access Policy (http://publicaccess.nih.gov/) which requires all scientists who receive grants from NIH to submit their peer-reviewed manuscripts to the digital archive PubMed Central upon acceptance for publication. The policy ensures that the public, which paid for the research through taxes, will have access to it within 12 months after publication in a journal.

Underscoring this pivotal federal mandate, the Harvard Faculty of Arts and Sciences voted to grant the university rights to deposit their scholarly articles in Harvard's open access repository. Various faculty constituencies on many other campuses, private and public, have adopted similar institutional OA mandates, notably MIT, University of Kansas and Columbia University. Duke University's Academic Council recently voted in support of establishing an open access repository for faculty works. At the University of Maryland, where an OA resolution was defeated in spring 2009, OA successfully re-emerged in March 2011 with the Senate voting by a wide margin to appoint a special task force that would "oversee and coordinate the development of both open-access awareness and policies." Advocates at the University of Pennsylvania and the University of North Texas are formulating draft OA policies as well. For the past decade or so, the proliferation of institutional OA mandates has been accompanied by an increase in the number of institutional repositories (IRs) that would house, preserve, provide wide access to and even publish peer-reviewed OA journals.

In addition to their educational efforts and their promotion of IRs, libraries are joining the revolutionary fight in other ways. Cornell University Library's recent announcement that it will not sign a contract for a licensed resource that requires non-disclosure of the agreement terms underscores the concerted effort on the part of libraries to negotiate for better terms such as shorter contract terms with opt-out clauses, less content bundling and lower prices.

However, as library budgets struggle to cover the perennially high inflation costs for continuing subscriptions to content, other financial solutions are desperately needed. For example, researchers now may designate a small fraction of their grant funding toward publication fees so that their articles 
can be OA. Given the small number of researchers who are able to do that, these efforts are not likely to have a huge impact on the financial picture. A more promising step is the emergence of multi-university initiatives such as Compact for Open Access Publishing Equity (www.oacompact.org/) and institutional open publishing support funds that encourage authors to consider OA publishing outlets by underwriting author fees.

Various faculty groups have also shown an inclination to experiment with non-traditional methods for managing the dissemination of scholarly work.

An example is the recent open peer review pilot attempted by the Shakespeare Quarterly (http://mediacommons.futureofthebook.org/mcpress/Shakespeare Quarterly_NewMedia/). The journal editors posted some papers that had been submitted for publication on the journal's website. They invited feedback from Shakespeare scholars and other readers on any essay that fell within their areas of expertise. Most importantly, they asked the reviewers to register in their own names so that authors could know the status and reputation of the reviewers. This process is very different from the secretive blind or double-blind review process traditionally used. If more journals would open up the review process like this, that would be a revolution in itself.

A few individual faculty members are looking for completely new ways to disseminate their work, such as creating podcasts that have the potential to reach huge audiences. For example, a junior professor and Tolkien scholar at a small school in Maryland took his scholarship public with a podcast and a website. With more than a million downloads, Corey Olsen is now an enormously popular medievalist, but it is not known yet whether he will get tenure for his popularity.

However, even with the endorsement of a federal mandate and campus activism over a number of years, OA has yet to become a leading business model in scholarly publishing. A number of complex and interrelated factors account for OA's non-emergence as a primary business model.

\section{What is stalling the revolution?}

Economic and cultural factors impede the revolution. The economic issues began after World War II. Before the war, most scholarly publishing was supported by not-for-profit professional and scholarly societies. After the war, the rapid growth of research in universities resulted in more papers being submitted for publication than the existing societies could handle. Faculty turned to commercial publishers, which initially led to healthy competition. With the resulting rapid growth in published journals, librarians wanted to select only those most needed and valued by their users.

Librarians identified the best or core journals of each discipline, hoping to satisfy most of their researchers' needs. They used tools such as Science Citation Index $(S C I)$ which traces citations for articles across all science journals and which developed a measure of the number of citations for each journal called the "impact factor," based on the assumption that the number of times articles are cited relates to their importance in the field. SCI measures only the impact of the journals it indexes; a journals' being indexed in SCI guarantees that it will be considered core. As the commercial publishers merged with other publishers and became large international companies, they were able to acquire more and more of the core journals. Librarians were eager to purchase them, paying whatever they cost. Thus the stage was set for astronomical subscription price increases. Today, the huge, profitable, publishing monoliths show no desire to reduce their profits willingly.

Long-established scholarly traditions and reward systems in universities contribute to the current cultural - and by extension, economic - pressures on the scholarly publishing system. To earn tenure, faculty members are expected to produce as many publications as possible in journals with established peer review and editorial practices. Highly ranked journals are often ones that the big commercial publishers have traditionally published or seek to acquire through mergers and acquisitions. For a junior professor whose tenure is at stake, publishing in those highly ranked journals with impressive impact factors and well-established publication histories is critical.

Librarians have been called the foot soldiers in this revolution for their efforts in trying to convince faculty members that open access is a viable alternative and in a scholar's best interests. As librarians have developed expertise in scholarly communication and copyright, they are better equipped to become more than foot soldiers in this revolution by adopting systematic strategies to address faculty lack of awareness in negotiating their author rights and establishing IRs for publishing faculty work. Many libraries have 
undertaken a suite of educational and programming efforts to raise faculty awareness of their rights as authors.

Nevertheless, most faculty members remain largely unaware of their ability - or are simply reluctant - to leverage their rights as authors in the publication process. In spite of evidence from many studies that making one's work freely available on the web greatly increases the use and citations of the work, faculty appear not to be making this a priority - perhaps for lack of time or knowledge. As the copyright owner of a work, the author can grant the publisher rights for a limited time to publish the work. Most authors are not negotiating their rights to optimize use of their own works postpublication. In our recent survey of faculty at the University of Maryland and Northwestern University, $89 \%$ of faculty respondents reported that when their articles are accepted for journal publication, they do not negotiate rights with the publishers before signing the copyright transfer agreements; they either read the agreements, sign and return them to publishers without changes $(60 \%)$ or they sign and return the agreements without even reading them (29\%). Our study will be a contribution to a growing body of literature reporting on faculty awareness of the scholarly communication system.

Because of faculty members' actions (or inactions), publishers become and remain the copyright owners of faculty-created work, thereby restricting access to scholarly content and collecting large profits. Another consequence of faculty unawareness of or reluctance to negotiate their author rights is the overall low deposit rate in institutional repositories. Despite a few notable exceptions - successful IRs with high deposit and download rates such as DSpace@MIT and the University of California's eScholarship - the vast majority of institutional IRs are continuing to define more effective strategies for recruiting scholarly content from faculty. Recent trends have shown that many repository managers have broadened their scope to include unique institutional content, including but not limited to the traditional peerreviewed article.

Raising individual faculty member's awareness at the grassroots level is critical as a first step toward collective action that will speed the revolution along. Successful institutional and multi-institutional repositories with article download rates in the millions will continue to serve as models for
IR development, content recruitment and publication services to campus constituencies. While these too will keep the OA revolution on a trajectory toward the desired goal, much more work needs to be done.

\section{How to nudge the revolution?}

Ultimately, federal mandates for OA that return the investment value of research to taxpayers will wield a great deal of influence in reform measures. The Federal Research Public Access Act (FRPAA), an alternate bill first introduced in 2006 by Senators Cornyn and Lieberman, takes a strong position for public access to taxpayer-funded research. However, it expired in the last Congress and will require reintroduction for a third time. In the meantime, earlier this year, President Obama signed the America COMPETES Reauthorization Act of 2010 (Public Law 111-358). America COMPETES (Creating Opportunities to Meaningfully Promote Excellence in Technology, Education and Science) seeks to establish a working group to examine issues related to the dissemination of research results funded by federal science agencies. America COMPETES does not defend a specific position on public or open access to research, thus leaving room for debate and by no means obviating the need for FRPAA. In fact there is strong support for FRRPAA in Congress, and it is not uncommon for a bill to be reintroduced several times before Congress takes action. Also, in the meantime, several federal agencies have been developing variations of the NIH mandate. For example, since September 2010 the National Science Foundation (NSF) requires open data sharing. The NSF Open Government Directive Plan is: "Unless shown otherwise, the default position shall be to make NSF data and information available in an open machine-readable format." (www.nsf.gov/pubs/2010/nsf10074/nsf10074.pdf). While this initiative is not without controversy - not all scientists agree that sharing their data is wise - nevertheless most believe that openness is a good thing.

\section{Will we ever get there?}

It is unlikely a single radical step will transform the current scholarly communication system into one with minimal legal and financial restrictions on valuable content while ensuring widespread availability of scholarly 
content. Instead, a combination of various strategies for a sustained period of time will gradually turn the tide. A transitional approach is perhaps even more effective than one that is abrupt and allows for celebration of smaller battles won.

It is sufficient for now that change is slow but steady. Intermediate but increasingly accepted transitional OA publishing models, such as author pay/hybrid examples, and delayed models in which articles are embargoed prior to obtaining OA status are important milestones on the path to open access as a preferred and fully accepted and economically feasible method of scholarly communication. The landscape remains ripe for more radical measures that might rapidly accelerate the OA revolution, but even without that, it seems that slow and steady will yet win the race.

\section{New ASIST Titles from Information Today, Inc.}

Information and Emotion:

The Emergent Affective

Paradigm in Information

Behavior Research and Theory

Edited by Diane Nahl and Dania Bilal ASIST member price $\$ 47.60$

\section{ARIST 41}

Edited by Blaise Cronin

ASIST member price $\$ 99.95$

Note: Prices do not include shipping and handling.

\section{Call for our current catalog or visit www.infotoday.com}

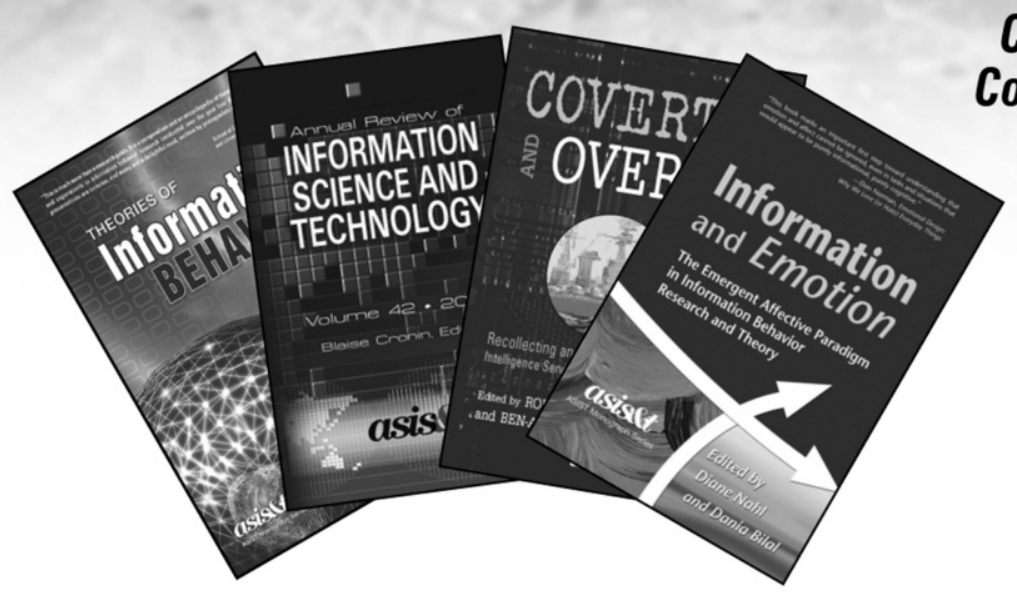

Covert and Overt: Recollecting and Connecting Intelligence Service and Information Science

Edited by Robert V. Williams and Ben-Ami Lipetz ASIST member price $\$ 39.60$

Theories of Information Behavior Edited by Karen E. Fisher, Sanda Erdelez, and Lynne (E. F.) McKechnie ASIST member price $\$ 39.60$

143 Old Marlton Pike • Medford, NJ 08055 - Phone: (800) 300-9868 or (609) 654-6266 • Fax: (609) 654-4309 E-mail: custserv@infotoday.com • Order online: www.infotoday.com 